\title{
Research on the Innovation of Digital art Teaching Method in the New Media Age
}

\author{
Liutong Zhang \\ College of Art, Digital Media Art Department, Xi'an University, Xi'an, Shaanxi, China, 710065
}

Keywords: new media; Digital art; teaching; innovation

Abstract: New media refers to the new forms of media appearing under the circumstance of informatization, which integrates information storage and dissemination with very distinctive features and advantages. The new media has a long-term and profound impact on people's daily work and study. In the field of education, the emergence of new media has also brought about great changes in education and teaching. This paper briefly introduces the characteristics of new media and presents the innovative methods to Digital art teaching under the environment of new media.

The term "new media" is no stranger to us, it is increasingly used on television and other media. The so-called new media, in a sense, refers to the environment where everything is medium. In short, it is more of an environment. The new media almost covers all the current digital media forms, including traditional network, online media, mobile media, digital TV and newspaper and so on. Because of its wide content, the new media is a broader concept. As far as the current application of new media is concerned, it mainly refers to utilize digital technology, network technology to provide information and entertainment services to specific users through the Internet, computers, mobile phones, digital TV terminals and other terminal devices. Therefore, the new media is also called digital new media.

With the development of science and technology and the progress of the times, new media is increasingly attracting attention from all walks of life. The rising prosperity of new media has also caused widespread concern in the academic community. Many scholars have carried out a long and systematic study of the application of new media in the field of education and teaching and have made many bold attempts, which in a word, has achieved great effects. New media has become a powerful auxiliary means in education and teaching.

\section{The characteristics of new media and its influence on traditional education}

Firstly, the new media is novel and vivid. It is a three-dimensional communication carrier and means of communication, which combines diversified manifestations such as sound, image and text. In the process of communication, it presents the dull and graphic contents in a novel and vivid form through the ways of color, light and shadow and text interactivity. Secondly, the new media technology has the function of massive information storage and centralized display. Finally, compared with traditional media, the new media has very strong interactive function, which makes the new media not only display contents passively, but also achieve the point to point 
communication and interactivity among parties. These characteristics and advantages the new media possesses make it widely applied in the field of education and teaching.

With the rapid development of new media technology and the deepening of technology, the use of new media for education and teaching has been widely applied in many schools. The application of new media technology poses a strong challenge to traditional education and teaching in many fields. Digital art, as a strongly interactive course, is mightily affected by this kind of impact. New media technology is beneficial to the transformation of traditional education concept of Digital art, and the change of Digital art teaching mode, teaching system, teaching contents and teaching methods. With the popularization of new media technology in and out of the class, the teaching methods of Digital art can be continuously improved. These are of great benefit to the implementation of quality-oriented education, the reduction of the academic burden of students and the motivation of the students' interest in learning. All in all, the impact of new media on traditional Digital art education can be summarized as follows:

\subsection{To promote the reform of traditional Digital art teaching methods}

The new media uses the networking platform as the learning tool where there is full of plentiful learning resources that students can collect and collate. This mode breaks traditional teaching method which focuses on teachers and highlights the students' subjectivity. At the same time, new media technology will also help teachers renew their ideas. With today's rapid development of science and technology, teachers are shouldering a special historical mission in cultivating students' innovative spirit. To cultivate the innovative spirit of students, the teachers themselves should be good at innovation. Otherwise, students will lose their soul and motivation. The application of new media technology in education and teaching contains lots of cutting-edge scientific and technological achievements. To some extent, the Digital art course under the environment of new media is a totally new course, which, based on information technology and network technology, extends to every field. To adapt to teaching through the new media, teachers must integrate and improve their knowledge structure and broaden their horizons. This process is the process of Digital art teachers' self-improvement and self-remolding, as well as the process of enhancing their selfinnovation. This will deeply influence Digital art teachers' understanding inwardly towards Digital art in the new media environment, which is not only an extension of ideological knowledge, but also an experience.

\subsection{To optimize lesson efficiency and improve the quality of teaching}

Under the environment of new media, college teachers can make high-quality courseware with plentiful contents and diversified forms, which meet students' preferences via modern technological means. Communication between students and teachers is no longer limited to time and space. It can occur anywhere and anytime. Teachers have no need to use chalk or a blackboard as they used to, but use computers, projectors and network terminals to push information such as pictures, texts, sounds, and images constantly. The Digital art Course under the new media environment has undergone great changes in the structure of information transmission and students' understanding, the integration of classroom time, and the ways of communication between teachers and students. Abundant and interesting teaching methods and teaching contents greatly arouse students' interest in learning and lead students to explore the unknown. Under the environment of new media, knowledge is no longer a dull symbol, but a fresh individual, which can stimulate students' cognition and understanding of Digital art, and can effectively improve the students' learning efficiency and memory, so as to optimize classroom efficiency and improve the quality of teaching. 


\subsection{To deepen teaching service and expand teaching space}

At present, Chinese institutions of higher learning have basically set up campus network. We should make full use of this resource, and then build new media curriculum system with school characteristics and features of related majors. At the school level, it should fully mobilize the enthusiasm of Digital art teachers and students, encourage teachers to work together, draw up new media programs in line with the development planning of relevant majors, organize teachers to collect, sort out and make related educational resources of Digital art, and establish a database of Digital art education. At the same time, it can organize students to sort out the collected learning materials, while teachers store their own courseware and other resources at specific addresses, which include audio resources, video resources, pictures and texts. Schools can launch the related teachers of science and engineering to develop simple and easy-to-use clients which meet the need of students, so that students can get into the information system at any time to obtain information quickly and effectively. In the meantime, the functions of interactive software and message board in the new media environment can open channels for the communication between teachers and students. Under the environment of new media, teaching and learning have broken the limitation of time and space, greatly expanding the space of education and teaching, and providing a practical guarantee for deepening teaching services.

\subsection{To improve students' practical ability effectively.}

With the integration of Internet, mobile phone, television network and other technologies, we make a new channel and means of cognitive and practical ability of things.Compared with traditional teaching modes of Digital art, the most essential characteristics of Digital art education in the new media environment is interactivity, and more and more Digital art courses are based on it. Interactivity enables students to professionalize and customize the Digital art learning, and change the traditional teaching ways where teachers play a leading role, making students explore actively rather than passively accepted, so as to improve students' practical ability when seeking knowledge. Obviously, this seemingly free education and teaching method can give full play to the initiative, enthusiasm and creativity of the students, and lay a solid foundation for the improvement of students' practical ability and the cultivation of their innovative ability.

\section{The Innovation of Digital art Teaching Method in the New Media Era.}

According to the requirements of the innovation and reform of Digital art Teaching in the new period, we should abandon the traditional Digital art teaching methods and carry out open Digital art teaching mode in a deeper and more extensive field. Under the general requirements of quality education, we should adhere to the people-oriented educational concept, highlight the leading role of students, utilize the plentiful resources of new media combined with tasks to drive teaching, scientifically, rationally and orderly arrange the students' learning tasks inside and outside the class, dig the students' potential through various ways and stimulate students' enthusiasm and initiative in learning, continuously cultivate students' ability to independently learn and lay a solid foundation for them to be qualified for jobs and to cultivate good habits. Our Digital art teaching should not only undertake the basic task of Digital art teaching, but also have the obligation to shape people in personality, conduct and so on, so that students have good thinking habits, higher cultural qualities, and strong sense of social responsibility and sense of mission. Digital art Teaching in the new media is a three-dimensional education mode, which can well adapt to the need of transformation of education and teaching. In the new media era, the innovation of Digital art teaching should focus on the following aspects: 


\subsection{To optimize and enrich teaching contents}

Under the teaching environment of new media, the introduction of interactive devices makes teachers have chances to offer more learning resources to students. The application of audio-visual and graphical materials has made teaching free from insipidity. Students' enthusiasm in learning can be fully aroused in the new media environment, and the teaching contents convert from plane structure to three-dimensional and diversified structure. For instance, when we play an Digital art video in the classroom, we can discuss the content of this video. Students can communicate with the teacher in real time at the interactive terminal for problems they meet, and teachers can organize discussions on some questions. If there are some topics that students are more concerned about, teachers can ask students to find out the answers by utilizing the repository of the new media.

\subsection{To expand the teaching space outside classroom}

In traditional Digital art learning, students are easily constrained by time, space and other circumstances. The new media, in the support of network technology, is not restricted by time and space, so that teachers and students can make flexible and convenient classroom interactivity at any time and in any place. In this way, students can make full use of their spare time. For example, the popular micro class nowadays is a very successful case of the expansion of teaching space under the environment of new media. At the same time, the application of teaching method of new media can effectively reduce the differences in learning ability caused by individual differences. Traditional Digital art teaching always ignore the differences of students, but to focus on teaching and pursue the standardization and consistency. Because of that, our education tends to stifle students' individuality and freedom, which harms to teach students in accordance with their aptitude. The new media technology makes the teaching idea of people oriented become possible, and students can explore learning resources independently and specifically according to their own tastes and choices.

\subsection{To cultivate students' art practical ability}

Digital art is a practical comprehensive course. The traditional teaching mode is difficult to improve student's undefined practical and practical ability in essence. In addition, under the traditional education mode, the practice of digital art for students is very single, students have been quite tired about this. The new media has opened up the broad space for the student practice activity, and the creation form is deeply loved by the students. At the same time, students can also exercise their own teamwork and innovation in these activities.

\section{Conclusion}

The modernized education and teaching methods of new media-oriented is an irresistible trend of the future Digital art education development. The wide application of new media technology must promote the growing modernization of Digital art teaching. The application of new media technology in Digital art teaching can effectively expand students' comprehensive ability and quality, enrich students' cultural view, strengthen the students' practical ability, and play an important role in improving the efficiency of Digital art teaching.

\section{References}

[1] Peng LAN. Where is the new media education in the era of convergence? [J]. news and writing, 2015 (3).

[2] Xu Peng. On the Special Contents and Methods of New Media Art Research [J].Journal of Renmin University of 
China, 2007 (1).

[3] Hu Xiao. The quality of domestic digital media art teachers should be [J]. art education, 2014 (3).

[4] Chao Jia. Teaching emphasis and teaching practice of digital media art [J]. teachers, 2012 (20).

[5] Jiang Xiaohua, Zhang Ruijing, Tang Lifang. The Four-in-One Practical Teaching of New Media Communication Specialty [J].Science and Education Cultural Collection, 2014 (20).

[6] Wang Jian, Yao Duozhong, Zhang Shuyu. Discussion on the Construction and Teaching Mode of Digital Media Technology Specialty in Higher Vocational Colleges [J].China Educational Technology Equipment, 2012, 15 (21): 15-17.

[7] Yang Xue, Qian Bingjiang. Thinking and Exploration on the Teaching Reform of Digital Media Specialty in Higher Vocational Colleges [J].Art Education Research, 2015, 24 (28): 178.

[8] Shumei. The Way of Cultivating Digital Media Arts Professionals in Higher Vocational Colleges [J].Journal of Tongren College, 2016, 01 (20): 189-191.

[9] Han Jianmin, Li Jie. Exploration and Practice of Teaching Reform of Digital Media Specialty in Higher Vocational Colleges [J].Education and Vocational, 2010, 03 (10): 104-105. 